\title{
Optimization study of binary metal oxides catalyzed transesterification system for biodiesel production
}

\begin{abstract}
The focus of this study is to produce biodiesel using non-edible feedstock (Jatropha curcas oil) via heterogeneous base catalyzed transesterification reaction. The solid base catalysts, binary metal oxide $(\mathrm{CaO}-\mathrm{ZnO}$ and $\mathrm{CaO}-\mathrm{La} 2 \mathrm{O} 3)$ were selected for the transesterification of high acid jatropha oil. Furthermore, the design of experiments was performed using 5-level-4 factor central composite design coupled with response surface methodology (RSM) in order to optimize the transesterification conditions. Four process factors were evaluated: (1) reaction time (1-5 h), (2) methanol/oil molar ratio (15:1-30:1), (3) reaction temperature $\left(40-200{ }^{\circ} \mathrm{C}\right)$ and (4) catalyst loading (1-5 wt.\%). Based on the quadratic model generated from RSM, reaction temperature rendered the most significant effect for both $\mathrm{CaO}-\mathrm{ZnO}$ and $\mathrm{CaO}-\mathrm{La} 2 \mathrm{O} 3$ catalyzed reactions, followed by catalyst loading and reaction time. Besides, both reaction models showed that interaction between reaction temperature with reaction time and catalyst loading has positively influenced the biodiesel yield. The highest conversion predicted for $\mathrm{CaO}-\mathrm{ZnO}$ and $\mathrm{CaO}-\mathrm{La} 2 \mathrm{O} 3$ catalyzed reactions was $97.03 \%$ and $96.27 \%$, respectively, with reasonable predictability and sufficient accuracy data (small error: 0.33-0.34\%). Furthermore, the physicochemical characteristics of produced biodiesel were tested with compliance to ASTM D7851 and EN 14124.
\end{abstract}

Keyword: Jatropha curcas oil; Response surface methodology; Catalyst; Optimization; Fuel properties; Transesterification; Mixed metal oxides; Statistical analysis 